\title{
Contrarreformas, Nova Gestão Pública e relações público- privadas: mapeando conceitos, tendências e influências na educação
}

\section{Counter-reforms, new public management and public-private relationships: mapping concepts, tendencies and influences in education Contrarreformas, nueva gestión pública y relaciones público-privadas: mapeando conceptos, tendencias e influencias en la educación}

MARILDA DE OLIVEIRA COSTA

\begin{abstract}
Resumo: A Nova Gestão Pública e as relações público-privadas emergiram de ondas de contrarreformas no papel do Estado e da sociedade a partir dos anos 1980. A internacionalização dessas medidas na área educacional dá-se por transferência, empréstimo ou convergência de políticas cujas origens se encontram em países anglo-saxões. Este estudo teórico objetiva mapear essas tendências em algumas políticas da educação nos países de origem, Portugal e Brasil.
\end{abstract}

Palavras-chave: Educação; contrarreformas; privatização.

\begin{abstract}
The New Public Management and public-private relationships have emerged from the waves of counter-reforms in the role of both the State and society, since the 1980s. The internationalization of these actions in the educational area occurs through transference, loan or convergence of policies whose origins are found in Anglo-Saxon countries. This theoretical study aims to map these tendencies in some educational policies in its countries of origin, Portugal and Brazil.
\end{abstract}

Keywords: counter-reforms; education; privatization.

Resumen: La Nueva Gestión Pública y las relaciones público-privadas surgieron de las olas de contrarreformas en el papel del Estado y de la sociedad, a partir de los años 80. La internacionalización de esas medidas en el área educativa se da por transferencia, préstamo o convergencia de políticas, cuyos orígenes se encuentran en países anglosajones. Este estudio teórico pretende trazar un mapa de estas tendencias en algunas políticas de educación en los países de origen, Portugal y Brasil.

Palabras clave: Educación; contrarreformas; privatización. 


\section{INTRODUÇÃO}

Este texto é parte de estudos desenvolvidos no pós-doutoramento em Ciências da Educação, na especialidade Administração e Organização Escolar, entre 2015 e 2016. Tem por objetivo mapear conceitos, tendências e influências da Nova Gestão Pública e relações público-privadas em algumas políticas de educação de países anglo-saxões, de Portugal e do Brasil, bem como analisar suas implicações para a privatização da educação.

A política educacional tem se constituído como importante campo de ações de uma multiplicidade de atores individuais e coletivos, públicos e privados, nacionais e internacionais, organizados em grandes redes, como vem se configurando no presente século; o exemplo mais visível é o da elaboração da Base Nacional Comum Curricular (ADRIÃO; PERONI, 2018) e da contrarreforma do ensino médio, em 2017 ambas no Brasil. Pode-se considerar que o movimento que culmina nessa nova arquitetura de políticas educacionais concebidas e implementadas pela chamada "Nova Direita" tem início nos finais dos anos 1980, marco inicial de reformas gerenciais, nomeadas por Hood (1991) New Public Management (NPM) e por Bresser Pereira (1998), no Brasil, administração pública gerencial. A partir da referida década, a responsabilidade do Estado com a educação "como atividade política e social complexa e que deve permanecer, em grande parte, se não totalmente, no setor público e a serviço de interesses públicos" (ROBERTSON; VERGER, 2012, p.1134) passou a ser questionada e tornou-se objeto de sérios ataques pelos defensores do livre mercado na área social e educacional, algo impensável até muito recentemente.

Estudiosos de diferentes temáticas e abordagens educacionais, em especial as áreas de política e administração têm despendido esforços para compreender e analisar as mudanças introduzidas nas referidas áreas a partir da década de 1980 e denunciar os riscos que as políticas implementadas sob a égide da 'modernização conservadora', baseadas em um 'fundamentalismo de mercado', trazem para a democratização da educação, um direito humano e um bem público, potencialmente emancipatório, de responsabilidade do Estado. Estudos como os de Ball (2001; 2004; 2007), Dale (2004), Chubb e Moe (1990), O’Neill (2011), Smyth (2011), Lima e Afonso (1993; 1995) e Lima (1996), só para citar alguns, realizados em espaços sociais e histórico-culturais onde as mudanças se fizeram sentir, primeiramente, apontavam/apontam os impactos da contrarreforma gerencial na área educacional.

1 Contrarreforma executada por meio da Medida Provisória $n^{\circ} 746 / 2016$, transformada na Lei $n^{\circ}$ $13.415 / 2017$ 
Essas medidas não tardariam a chegar a países da América Latina - dentre eles, o Brasil-, que, na contramão de medidas neoconservadoras adotadas em países de capitalismo central, passavam por um processo de abertura política e transição para regimes democráticos das ditaduras militares implantadas no continente latino-americano nas décadas de 1960 e 1970. Porém, como adverte Boron (2003), as expectativas com a democracia geradas com a abertura política dos anos de 1980 foram frustradas por medidas neoliberais de austeridade induzidas pelos organismos multilaterais via Consenso de Washington. As mudanças nas áreas econômica e social, no papel do Estado, da administração pública e da política e administração educacional, a partir da década de 1990 no Brasil, são complexas e têm despertado múltiplos interesses de governos, agências internacionais, empresários de diversos ramos - sobretudo, o financeiro - e movimentos populares, acadêmicos e científicos da área educacional, tornando-se importante bjeto de estudo e pesquisa acadêmica (OLIVEIRA, 1997; 2001, DOURADO; PARO, 2001; PERONI, 2003; SHIROMA, MORAES e EVANGELISTA, 2004; NEVES, 2005). A complexidade das mudanças na área educacional tornar-se-ia mais visível alguns anos após as contrarreformas do Estado e da educação no país, na década de 1990, introduzidas por meio do Plano Diretor da Reforma do Estado do Aparelho do Estado - PDRAE, (BRASIL, 1995).

A partir da referida década, surgem arranjos ainda mais complexos, que vão da concepção à oferta educacional. A educação passou a ser objeto, dentre inúmeras medidas de racionalização técnica, de diversos arranjos entre as esferas pública e privada. Segundo Robertson e Verger (2012), “as 'parcerias' surgiram no início de 1990 como um promissor mecanismo para minimizar os danos causados por formas anteriores de privatização, ainda que sem abandoná-las” (p.1134). Discursivamente, “a participação do privado está se firmando rapidamente como um melhor caminho (the one best way) para pensar a respeito da futura cessão do setor público". (BALL, 2004, p.1122).

É, portanto, no contexto acima que se situa este estudo. Mais precisamente, sobre as contrarreformas da educação e a influência da Nova Gestão Pública e de relações público-privadas na educação, como apontado anteriormente.

\section{CONTRARREFORMAS NO PAPEL DO ESTADO E DA EDUCAÇÃO E RELAÇÕES PÚBLICO-PRIVADAS}

As contrarreformas no papel do Estado e da educação, a partir da década de 1980, têm sido frequentemente tratadas como parte de um conjunto de valores de inspiração neoliberal e neoconservadora, baseados no mercado, com vistas a adequar a educação à competitividade internacional. Como assinala Ball 
(2007), trata-se da educação como objeto de lucro, apresentada sob uma forma contratável e comercializável; a educação "tem sido o factor chave no forçar dos limites competitivos dos estados em relação uns aos outros" (DALE, 2004, p.446). Nesse sentido,

Não é mais possível ver as políticas educacionais apenas do ponto de vista do Estado-nação: a educação é um assunto de políticas regional e global e cada vez mais um assunto de comércio internacional. A educação é, em vários sentidos, uma oportunidade de negócios (BALL, 2004, p.1108).

O aprofundamento de viés mercantilista e financeirizado nas políticas sociais está cada vez mais presente nas políticas educacionais de todo o mundo, tendo início com as primeiras reformas da década de 1980, em países de capitalismo central. Nesse contexto, a ideia de Estado provedor foi substituída pela de "Estado de Competição", e seu papel é promover e monitorar a oferta de serviços públicos por agentes privados, o que não "significa que o Estado seja menos ativo ou menos intruso, mas que age de modo diferente". (BALL, 2004, p.1109).

Mesmo com as ressalvas de Ball (2007) de que "não existe retorno a um passado em que o setor público como um todo funcionava bem e trabalhava com justiça no interesse de todos os aprendizes" (BALL, 2007, p. 187), a ideia de educação enquanto direito humano e bem público, construída sobre os pilares da modernidade, nunca foi tão seriamente atacada e ameaçada como vem ocorrendo a partir das reformas neoliberais e neoconservadoras do último quarto de século XX e no presente século, em diferentes contextos.

Como adverte Dale (2004), há uma agenda globalmente estruturada para a educação, materializada como empréstimo, convergência e transferência de políticas que se acomodam às especificidades históricas e culturais de cada país. Portanto, cada continente, região ou país dentro do mesmo continente, ou meso e microrregiões dentro do mesmo país, como no Brasil, reelabora e implementa as reformas de maneira muito diversificada, como também são seus impactos.

Segundo Ball (2007), pode-se considerar que a Inglaterra foi o laboratório das reformas educacionais neoconservadoras e, por isso, também exportadora de tais ideias para outras regiões do mundo. Ball, referindo-se às reformas no Reino Unido, afirmou: 
Escolas no Reino Unido estão actualmente confrontadas com um pacote de reformas que inclui não só um novo currículo nacional, mas também mudanças na governança escolar, gestão e financiamento, mudanças nos papéis das autoridades locais foi demonstrado em testes de estudante e inspecção escolar, na pedagogia e na organização da sala de aula e mudanças na formação de professores, nas condições de trabalho e de emprego dos professores. (BALL, 2004, p.63).

O caráter autoritário e instável das reformas foi também observado e analisado pelo autor. Medidas e consultas encomendadas e adotadas eram descartadas e ignoradas com a mesma velocidade (racionalidades adotadas, historicamente debatidas e descartadas nas Ciências Humanas e Sociais), e delas eram excluídas representações de professores. O impacto dessas reformas, separadas ou em conjunto, promoveu "mudanças profundas na natureza do ensino e no papel dos professores, nas relações entre as escolas e os pais e na natureza das escolas como organizações de trabalho" (BALL, 2004, p. 63-64), como advertiu o autor. O potencial das reformas para alterações de longo alcance nos sistemas educacionais foi também percebido na pesquisa:

Em termos gerais, as reformas e as formas de controle que incorporam podem ser representadas por três grupos: o currículo, o mercado, e a gestão. Em particular, o mercado e gestão são amarrados juntos na reformulação de orientação e propósito nas escolas. Gestão desempenha um papel chave no fornecimento de outras alterações. (Idem, p. 64).

$\mathrm{O}$ autor afirma que essas mudanças introduzidas com as reformas atingiram o Reino Unido, e não somente a Inglaterra. Durante as décadas de 1980 e 1990, as reformas orientadas com base no modelo do setor privado levaram ao desmantelamento do Welfare State por meio de cortes e privatização, desregulamentação e uma nova ênfase na escolha individual e no consumo, ou seja, o corte de gastos e a privatização ocuparam o centro do debate político a partir das referidas décadas. (BALL, 2007). Esse autor apresenta e analisa a privatização conservadora, as rupturas e as continuidades dessas reformas nas políticas de Terceira Via na Inglaterra.

O Partido Conservador promoveu uma estrutura de possibilidades, o que permitiu que as empresas marcassem presença na prestação de serviços de educação e outras políticas, entre elas, a Gestão Local de Escolas (Ibidem). A política do New Labour não rompeu com todas as políticas conservadoras; retomou e deu continuidade à ACT (Licitação Competitiva Obrigatória) e CTCs (City Technology Colleges). Mais ainda:

As mudanças na educação e política (policy) social desde 1988 podem ser entendidas como um efeito catraca de mudar possibilidades práticas e discursivas. Este 
continua a ser o caso no âmbito do New Labour, um processo passo-a-passo de romper os modos estabelecidos de operação e tomadas como certas práticas, a introdução de novas liberdades, novos trabalhos e novos tipos de relacionamentos. (BALL, 2007, p.19).

Ball chama atenção para as transformações geradas com a modernização, que envolvem aspectos "criativos e destrutivos, um processo de atrito e reinvenção. [...] As facetas destrutivas da transformação envolvem desestabiliz̧ação, desinvestimento e mercantilização". (Idem, p.19-20). Na base desses conceitos, encontra-se a explicação para as continuidades e rupturas entre neoliberalismo e Terceira Via, ou seja, entre as políticas conservadoras e social-democratas do novo trabalhismo (New Labour). Os discursos bem elaborados e articulados, e as narrativas daí decorrentes oferecem uma "linguagem e práticas em torno das quais o setor público está sendo reformado” (BALL, 2007, p.1). A desestabilização é produto dessa linguagem, que, a partir de "um discurso hegemônico, de perfeição romântica que representa o privado e comercializa formas e soluções mágicas para os problemas do setor público", tem oferecido, ou melhor, vendido tais soluções para os "problemas" da educação. (Idem, p.19-20). Esses discursos, parte da retórica neoliberal que apresenta o privado como alternativa à 'ineficiência e ineficácia’ do setor público, foram retomados e ressignificados pela Terceira Via.

Segundo Ball, o "neoliberalismo e a Terceira Via são os mesmos e diferentes. Eles são diferentes tipos de combinações políticas (policy)”. A Terceira Via "não seria possível sem o neoliberalismo, mas difere em aspectos importantes em termos do papel do Estado e suas relações com os setores público e privado, entre outras coisas" (Idem, p. 20). A Terceira Via é um fenômeno político muito mais complexo. O governo moderno tem um papel estratégico para não substituir o mercado, mas garantir que ele funcione 'adequadamente'. Os limites de mecanismos de mercado tiveram de ser "re-aprendidos, e outras formas de coordenação para completar, complementar ou compensar as insuficiências do mercado tiveram de ser re-inventadas", ainda que "disfarçadas por trás de nomes alterados, discursos inovadores, políticas e volume de negócios e agitação institucional” (BALL, 2007, p. 21-22). A desestabilização, por ser uma componente ideológica e discursiva de modernização conservadora, ganhou força e foi redimensionada pela Terceira Via. As consequências mais visíveis para a área educacional foram os diferentes arranjos entre setores público e privado na área, começando em finais dos anos 1990, época a partir da qual o papel do Estado se tornou muito mais complexo que no período anterior, como também ficou a dificuldade em definir um corpus teórico capaz de explicá-lo: 
Já não podemos convocar, sem profundas atualizações, algumas teorias disponíveis sobre o estado, também não poderemos deixar de considerar que o estado, em si mesmo, enquanto sujeito histórico e político, continua a existir, pelo que continuamos a precisar de teorias que dêem conta da redefinição do seu papel e que sejam capazes de explicar quais os limites e possibilidades da sua acção no contexto das novas condicionantes mega-estruturais (AFONSO, 2009, p.36).

O 'desinvestimento' (ou 'reinvestimento') refere-se não somente às políticas de governos conservadores das décadas de 1980 e 1990, marcadas por cortes fulminantes nos gastos públicos (FLYNN, 1993), mas também a novas formas de controle financeiro e dotação financeira sob o New Labour. Segundo Ball, esta política do New Labour é importante em dois sentidos:

O primeiro é uma forma de redistribuição de financiamento no âmbito do setor público relacionada com indicadores de desempenho ou de sucesso competitivo e uma utilização crescente de financiamento e sistemas de licitação, programa orientado para conseguir re-focagem e re-desenho institucional. O segundo é uma redistribuição de fundos, longe de financiamento direto, das organizações do setor público e autoridades locais para contrair financiamento de organizações privadas, voluntárias e quase-públicas para a prestação de serviços públicos. (BALL, 2007, p.22).

O terceiro elemento da reforma, ou seja, a 'mercantilização', surge como um modo de transformação das relações sociais e processos públicos em formas que são mensuráveis e, assim, acreditáveis ou comerciáveis, e criação de espaços para a privatização dentro do setor público. (BALL, 2007). A "mercantilização é causa e efeito em relação à privatização" (p. 23). A performatividade, ou parte dela é, segundo Ball, a "re-imaginação técnica e discursiva da educação como uma mercadoria" (Ibidem). Ainda, conforme este autor:

Em um nível prático de re-design organizacional há três facetas distintas, porém relacionadas à criatividade destrutiva do processo de transformação ou reforma. Três diferentes tecnologias políticas (policy) agiram em cima e dentro do sector público - mercados, (novo) gerencialismo (ou Nova Gestão Pública) e performatividade. (Idem, p.24).

Apesar de diferentes, atuando conjuntamente, as três tecnologias têm alterado o formato das organizações educativas, e "cada uma tem também contribuído de maneira particular, para os processos de privatização. Cada tecnologia é uma forma de disciplina e regulação, e juntas elas constituem um novo regime de regulamentação do sector público" (Ibidem). Não somente no Reino Unido, mas em vários países, as reformas educacionais têm sido informadas por estas tecnologias, tal como os casos de escolas de autogerenciamento (Self Managing Schools - SMS) na Nova Zelândia, Austrália, Estados Unidos, Inglaterra, 
Canadá, há mais de três décadas. (SMYTH, 2011). Esses casos podem ser alguns exemplos da forma como o modelo com base no mercado tem influenciado a política educacional de inúmeros países centrais, (semi)periféricos, como Portugal, e periféricos, incluindo-se o Brasil. Como apontam Smyth (2011), O`Neill (2011) e Court e O'Neill (2011), a apropriação discursiva e prática de iniciativas de autogerenciamento das escolas pelos reformadores pode ser considerada um desastre para a educação pública, especialmente para os mais pobres, nestes países.

Análises de Chubb e Moe (1990) sobre a onda de reformas nos Estados Unidos apontaram que elas tiveram por base o relatório $A$ Nation at Risk, de 1983, o qual trouxe recomendações para promover a excelência em educação. As reformas promovidas em cada estado, conjuntamente, foram associadas ao ensino eficaz:

Os requisitos de graduação mais rigorosos, normas mais rigorosas para a certificação de professores, salários mais elevados dos professores, planos de carreira e (ocasionalmente) pagamento por mérito para professores, mais rigorosa política disciplinar, mais lição de casa, dias ou anos escolares mais longos, e uma maior dependência em testes padronizados de desempenho dos estudantes, entre outros. (CHUBB; MOE, 1990, p.11).

Segundo os autores, próximo do final da década de 1980, a primeira onda de reformas foi seguida por deliberação pública de proposta de grande alcance que mexeu com a engenharia das escolas, por meio de gestão baseada na escola, capacitação de professores e profissionalismo, e de escolha controlada para os pais e alunos. Essa foi considerada a segunda onda de reformas em curso até início de 1990. Conforme os autores, até aquele momento, haviam "alcançado sucesso político em um número limitado de distritos em todo o país" (CHUBB; MOE, 1990, p.11). Na fase posterior à publicação do referido relatório, "os conceitos de accountability e de high-stakes testing começaram a ser referenciados e implementados de forma crescente", afirma Afonso (2009, p.19). O conceito de accountability tal como tem sido utilizado a partir das reformas neoliberal e neoconservadora, a exemplo da reforma da educação de George W. Bush, conhecida como No Child Left Behind Act, "baseia-se nos resultados dos testes estandardizados e inclui sanções, recompensas ou intervenções, dirigidas tanto a distritos escolares como a estabelecimentos de ensino, professores e estudantes" (Idem, p.14). O outro conceito de avaliação, high-stakes testing, também muito utilizado a partir da reforma, refere-se 
À realização de testes que têm importantes implicações para os avaliados, nomeadamente pela possibilidade de acesso a certificados e graus acadêmicos e pela atribuição de recompensas ou sanções em função da prossecução ou não de objectivos precisos em matéria de sucesso escolar, podendo ir, neste último caso, até ao encerramento das escolas que não atinjam determinados níveis (AFONSO, 2009, p. 18-19).

Para o autor, o termo accountability, por exemplo, da forma descrita acima, só passou a ser utilizado a partir da década de 1980, com as reformas de governos conservadores nos Estados Unidos e na Inglaterra. Pela natureza híbrida desses governos, que mesclam as ideologias neoliberal e neoconservadora, "constituem exemplos paradigmáticos de viragem nos modos de governação dos sistemas educativos", em especial pelo uso de avaliações externas, "baseadas em testes estandardizados, como estratégia de indução de medidas de privatização e/ou lógicas de quase-mercado em educação, mas também de aumento do controlo central do Estado" (Idem. p.19).

Lima e Afonso (1993), ao tratarem da chegada dessas ideias a Portugal e das reformas emergentes, como a Lei de Bases do Sistema Educativo (LBSE) de 1986, avaliam as diferenças do caso português com relação a outras reformas: "o que há, talvez, de específico no caso português é o tipo de ruptura com o discurso da democratização, fortemente enraizado na política educativa desde 1974 (e até mesmo antes), e a tentativa de articular aquele discurso com a ideologia da modernização" (LIMA; AFONSO, 1993, p.34). Lima (2002) analisa as ambiguidades entre duas agendas que aparentemente usavam o mesmo vocábulo: "a agenda democrática e descentralizadora e a agenda modernizadora e tecnocrática” (p. 65). Segundo o autor, "as vertentes democráticas, participativas, descentralizadoras e autonômicas representavam, assim, algumas das idéias, das promessas e das esperanças, mais significativas de certa fase, inicial, dos discursos sobre a reforma educativa". (Ibidem). Entretanto, "a mudança efetiva no sistema de gestão implica mais do que uma retórica reformista que valoriza discursivamente participação e autonomia, mas, na prática, estava a implementar medidas contraditórias" (LIMA; AFONSO, 1995, p.170).

Ball e Olmedo (2013) analisam as mais recentes relações ou redes de políticas globais em educação no contexto da nova filantropia e do capitalismo social. Citam os novos filantropos, que vêm operando em nível global. Nessa perspectiva, soluções inovadoras e velhas soluções para problemas sociais e de desenvolvimento baseadas no mercado estão sendo privilegiadas e fortalecidas "através do surgimento de uma nova elite global, conectada em rede, formada por promotores de políticas e novos filantropos" (BALL; OLMEDO, 2013, p. 33). Os autores alertam que "essa tomada de responsabilidade por parte de uma nova 
filantropia e do capitalismo social também levanta questões fundamentais sobre participação democrática e responsabilidade dos governos e outras instituições públicas na provisão de serviços sociais e direitos civis" (Idem, p.34).

$\mathrm{Na}$ área educacional, a receita são as Charter Schools dos Estados Unidos. Apresentadas como inovação e solução rápida e flexível, "pressupõem uma concomitante estandardização da avaliação, dos métodos de ensino e do currículo e rejeitam formas alternativas de intervenção educacional e transformação social" (Idem, p. 39). Os reformadores/filantropos/empresários apontam as vantagens das escolas charter e escamoteiam os problemas envolvidos na relação entre Estado e organizações responsáveis pela gestão dessas escolas, em especial no tocante a fraude financeira, desperdício, abuso e má gestão, conforme exposto no relatório The Tip of the Iceberg - Charter Cchool, Vulnerabilities to Waste, Frand and Abuse, produzido em abril de 2015 por duas organizações do terceiro setor nos Estados Unidos: The Center Popular Democracy e The Alliance to Reclaim our Schools. No referido relatório, essas organizações demonstram índices alarmantes de recursos públicos usurpados nas escolas charter - no ano de 2014, as escolas charter em 16 estados (cerca de um terço dos estados com escolas charter) tinham experimentado mais de U\$ 100 milhões em relato de fraude, desperdício, abuso e má gestão. Essas evidências podem ser apenas a ponta do iceberg frente a levantamento dos últimos 12 meses que apontam um novo total - acima de U\$200.000.000 -, afirma o relatório.

Não é novidade que esses princípios têm constituído a semântica dos discursos, tanto de governos da nova direita quanto de orientação trabalhista e/ ou "social democratas", de diversos países, assim como têm orientado agendas de instituições e organizações multilaterais voltadas para reformas educacionais mais recentes, especialmente a partir dos anos 2000. Organismos e instituições multilaterais, principalmente a Organização das Nações Unidas para a Educação, Ciência e Cultura (UNESCO), o Banco Mundial (BM) e a Organização para a Cooperação e Desenvolvimento Econômico (OCDE), têm traçado políticas globais para a educação, com destaque para a $\mathrm{OCDE},{ }^{2}$ cujas políticas ou agenda educacional focalizam os testes padronizados, como o Programa Internacional de Avaliação de Alunos (PISA), aplicado não só a estudantes de países membros. Os resultados do PISA têm sido utilizados para estabelecer rankings entre diferentes nações e induzir políticas e práticas locais que levam àquilo que Lima (1996) já denunciava sobre a educação contábil. Assim como adverte Afonso (2009) 
ao problematizar a relação entre accountability, testes estandardizados e rankings escolares, "avaliação, prestação de contas e responsabilização nem sempre constituem elementos que se potenciem mutuamente, e nem sempre se integram em orientações e relações guiadas por uma intencionalidade democrática e de empowerment dos cidadãos" (p.16).

Resultados dos testes estandardizados no Brasil têm sido utilizados para orientar a elaboração de políticas educacionais e se constituído também em álibi para governos estaduais e municipais estabelecerem diferentes e complexas relações com o setor privado, como parcerias, contratos de gestão ao estilo das charter schools e compras de materiais apostilados, entre outras, em nome de uma pretensa qualidade que o setor privado discursivamente oferece. (AMARAL, 2014; COSTA \& AMARAL, 2015; ADRIÃO \& PERONI, 2018; COSTA, 2019). Teodoro e Torres (2005), ao tratarem de uma agenda hegemônica global neoliberal para a educação não superior, afirmam que tal agenda "prioriza a privatização e a descentralização das formas públicas de educação, o estabelecimento de standards educacionais, uma forte ênfase nos exames e testes nacionais, e um focus na accountability" (p.13).

Os temas e conceitos tratados acima têm influenciado reformas educacionais dos anos 1980 à atualidade. No Brasil, acentuadamente a partir da segunda metade da década de 1990, as reformas do Estado e da educação alteraram princípios constitucionais, como a gestão democrática do ensino público (BRASIL, 1988, Art. 206, VI), e direitos, como a obrigatoriedade do ensino somente de 07 a 14 anos, entre outras medidas de racionalização, tratadas no próximo item.

\section{MAPEANDO INFLUÊNCIAS DE CONTRARREFORMAS EDUCACIONAIS NO CONTEXTO NACIONAL}

Pesquisadores da política educacional dos anos de 1990, entre eles, Peroni (2003), Neves (2005) e Shiroma, Moraes e Evangelista (2004), já apontavam a influência de uma agenda encetada por organismos multilaterais na educação nacional cuja Reforma do Aparelho do Estado, no Brasil, deu impulso definitivo. Shiroma, Moraes e Evangelista (2004), por exemplo, analisaram a política educacional da referida década no Brasil e apontaram a influência de uma agenda de viés mercadológico lançada por organismos supranacionais, dentre eles, UNESCO e Banco Mundial, assim como organizações do setor empresarial brasileiro. As autoras apontaram a educação como importante fator de competitividade, nacional e internacional, tal como defende Porter (1993), e recomendaram ações no campo. Já Neves (2005) evidenciou a Terceira Via 
como estratégia do capital para educar o consenso. Não por acaso, tais princípios influenciariam a agenda das políticas educacionais a partir da década de 1990, como ficou patente na elaboração da Lei de Diretrizes e Bases da Educação Nacional (LDB), Lei no 9.394/1996 (BRASIL, 1996).

Por meio do Art. 20, incisos I a IV da LDB no 9394/96, foram abertas as possibilidades para instituições do setor privado 'sem fins lucrativos', tais como as instituições comunitárias, confessionais e filantrópicas, receberem recursos públicos, ou seja, de forma 'camuflada', a LDB assegurou as relações público-privadas na educação e, de forma explícita, o Plano Diretor de Reforma do Aparelho do Estado, com a figura jurídica do público não estatal (BRASIL, 1995), a regulamentação do trabalho voluntário (Lei 71/1998) BRASIL,19983, a institucionalização de Organizações Sociais (OS) (Lei no 9.637/1998) (BRASIL, 1998) e Organizações da Sociedade Civil de Interesse Público (OSCIPs) (Lei no $^{\circ}$ 9. 790/1999) (BRASIL, 1999) .

Abertas as possibilidades de relações com o setor privado no Brasil, em tese, não lucrativas, formas de trabalho voluntário nas escolas, como "Amigos da Escola", foram incentivadas pelos mass media, especialmente canais de televisão das organizações Globo. O setor econômico e financeiro criou e/ou ressignificou suas fundações em outros parâmetros, consideradas o braço social da empresa. A ação social, ou a nova filantropia (BALL; OLMEDO, 2013), por elas promovida, aparentemente, tem mais que uma via de mão dupla, pois, além de assegurar ao empresariado o título de "empresário cidadão" e à empresa o título de "socialmente responsável”, delimita conteúdo da educação com um currículo mínimo e, acima de tudo, visa ao lucro. Estudo de Silva e Souza (2009) apontou que a participação do empresariado na gestão da educação vai muito além destes títulos:

Evidenciam que a participação do empresariado na gestão da escola pública não está provida apenas de um cariz técnico e operacional para garantir sua eficiência e produtividade, tampouco está movida por ações filantrópicas ou "socialmente responsáveis". Tal participação está ancorada por forte conteúdo ideológico que opera na esfera cultural e política com alguns desdobramentos sobre o "currículo oculto" da escola (SILVA; SOUZA, 2009, p.784).

\footnotetext{
3 Visa a promover e garantir a todos os cidadãos a participação solidária em acções de voluntariado e definir as bases do seu enquadramento jurídico.

4 Dispõe sobre a qualificação de entidades como organizações sociais, a criação do Programa Nacional de Publicização, a extinção dos órgãos e entidades que menciona e a absorção de suas atividades por organizações sociais.

5 Dispõe sobre a qualificação de pessoas jurídicas de direito privado, sem fins lucrativos, como Organizações da Sociedade Civil de Interesse Público, e institui e disciplina o Termo de Parceria.
} 
As autoras analisam os desdobramentos do "currículo oculto" na formação do estudante; tal currículo, em última instância, teria por finalidade moldar corpos e mentes para adequá-los à nova fase de reestruturação produtiva. A exemplo de outros países, também no Brasil governos oriundos do Partido dos Trabalhadores (PT) não romperam com aspectos importantes da agenda em curso que levam à privatização da educação, tais como a atuação de instituições não estatais, como ONGs, fundações, institutos e, mais recentemente, Organizações Sociais (OS), incluindo-se o campo das políticas de avaliação em larga escala. Pelo contrário, foi criado em 2007 o Índice de Desenvolvimento da Educação Básica (IDEB) ${ }^{6}$, com a finalidade de medir a qualidade da educação por meio de metas para cada escola e redes de ensino, com o objetivo de alcançar 6,0 até 2021, média do sistema educacional dos países desenvolvidos. Assim como as avaliações estandardizadas, o IDEB é bastante criticado por não representar na íntegra a realidade educacional, especialmente no que se refere à interferência de fatores externos nos processos de aprendizagem escolar, e potencializar rankings entre escolas e sistemas de ensino.

A materialização de princípios da Nova Gestão Pública na educação no Brasil, iniciada com as reformas da década de 1990, não levou à privatização direta na área, como tem ocorrido na Inglaterra, EUA, Chile, Austrália e Nova Zelândia, primeiros países a implementarem medidas com base em princípios de mercado nos sistemas educativos. (SMYTH, 2011). Porém, a reforma educacional materializada com e a partir da LDB (Lei n. 9394/96) abriu possibilidades para criação de complexos arranjos entre setores público e privado, da elaboração à execução de políticas; abertura para a competição e criação de quase-mercados no interior dos sistemas públicos de ensino; aquisição de material didático/ apostilado pelo poder público; indústria das avaliações; e contratos de gestão com Organizações Sociais (OS), entre outras. Muito semelhante ao que ocorreu em Portugal com o discurso da modernização, no Brasil, a semântica da modernização conservadora apropriou-se de termos constitutivos da gestão democrática, como seus fundamentos e mecanismos, atribuindo-lhes novos significados. Nesse contexto, há diferentes formas de conjugar o verbo privatizar, como analisa Lima (2013). Para o autor, a privatização na área da gestão pode significar

6 O IDEB foi criado pelo Inep em 2007; reune em um só indicador dois conceitos para medir a qualidade da educação: fluxo escolar e médias de desempenho nas avaliações. Fonte: http://portal.inep.gov.br/ web/portal-ideb/o-que-e-o-ideb. Acessado em 11 de março de 2016. 
A crescente introdução de modos de gestão considerados típicos das organizações privadas, ideologicamente consideradas bem geridas, em busca da "zeroburocracia", mais ágeis e manejáveis em ambientes incertos e turbulentos, centradas nas necessidades do cliente ou consumidor, induzindo a competitividade no seu interior através da adoção de mercados internos, ou seja, seguindo os princípios normativos e as prescrições técnico-instrumentais da chamada "Nova Gestão Pública", que tenho associado ao que designo por 'cânone gerencialista'. (LIMA, 2013, p.179).

A ênfase na gestão é observada em praticamente todos os países que passaram por reformas. Nas políticas tecnocráticas e racionalizadoras no campo da gestão encontradas no Reino Unido, nas décadas de 1980 e 1990, o poder da gestão e os gestores foram vistos como sujeitos mágicos "que podiam transformar organizações consideradas em falência, torná-las um recurso muito significativo para os governos, que buscavam reconfigurar estados de bem-estar e serviços públicos." (NEWMAN, 2012, p. 361).

Técnicas de gerenciamento que habitavam o mundo dos negócios, considerado mais empreendedor e dinâmico, foram a alternativa ao regime burocrático-profissional e a formas mais democráticas de gestão, como o autogerenciamento das escolas. Nesses termos, "o gerencialismo revela-se, com frequência, mais gestão para menos democracia, sendo responsável por um aumento exponencial de certas dimensões da burocracia racional, estudadas por Max Weber", ao mesmo tempo "de dimensões menos racionais e mais coincidentes com a aceção pejorativa e de senso comum" (LIMA, 2013, p.68).

Sob o gerencialismo, a gestão e o papel de gestores foram redefinidos, e a liderança eficaz com base na competência técnica se sobrepôs à competência política. Esta última, muito valorizada na perspectiva democrática, foi relegada a último plano, e a eleição de diretores segue certos rituais, nos quais o conhecimento de normas, leis e regulamentos sobrepõe-se a outras capacidades, como a política e didático-pedagógica, tal como observado em documentos e materiais de administração escolar difundidos pelo Instituto Ayrton Senna (IAS) (ADRIÃO; PERONI, 2010, et al.). Contrária a afirmações que apontam o surgimento de um modelo pós-burocrático mais flexível das organizações, a perspectiva gerencialista adotada levou àquilo que Lima (2012) tem observado a respeito da associação entre gerencialismo + novas tecnologias + burocracia:

Trata de uma burocracia aumentada, resultante de um processo de hibridização que ora perde, ora mantém, certos traços da burocracia weberiana, que associa, eventualmente, novas dimensões ao "tipo ideal" original, que adquire novas e mais complexas propriedades de extensão e de controle, entre outras, induzida por uma burocracia digital, ciberburocracia. (LIMA; 2012, p.130). 
O gerencialismo tem-se apresentado como a solução eficiente e eficaz a outras formas de gestão, como a burocrática e a democrática, por exemplo. No tocante ao aspecto burocrático, a conjugação entre as três perspectivas apontadas pelo autor pode levar a "uma acrescida fiabilidade e capacidade de cálculo racional, de maior velocidade, capacidade de armazenar, gerir e transportar dados, compatível com a lógica de modernização e respectiva valorização da racionalidade técnico-instrumental estudada e criticada" por Max Weber "e com o processo de racionalização inerente à sociedade moderna e às organizações públicas e privadas de todo tipo" (Ibidem). Com relação à abordagem democrática, Smyth (2011), Ball (2004) e Lima e Afonso (1993) mostram como a ressemantização de conceitos de gestão democrática alterou a gestão de escolas por meio de iniciativas de autogerenciamento. Segundo Ball, "o ponto principal entre gestão e mercado é que eles não são formas de controle, tanto quanto a relação entre educação e Estado está em causa. Consequentemente, a gestão é transformada em autogerenciamento com toda a confusão semântica e ideológica que traz" (BALL, 2004, p.64).

\section{CONSIDERAÇÕES}

Este texto teve por objetivo mapear aspectos de contrarreformas NPM e de relações público-privadas no campo educacional em países centrais, como Inglaterra, Estados Unidos, Portugal e Brasil. Os autores selecionados para fundamentar o estudo forneceram subsídios teórico-conceituais necessários à compreensão das contrarreformas neoliberais, conservadoras e de Terceira Via nos diferentes contextos selecionados e de seus impactos nas áreas de política e administração educacional.

A onda de contrarreformas realizadas ao longo do último quarto do século XX e no presente século tem alterado a configuração do poder dos Estados na provisão de direitos e na promoção de políticas sociais e educacionais de caráter público e democrático voltadas para a formação cidadã, participativa e, quiçá, emancipatória. O mapeamento de contrarreformas tipo NPM e das relações público-privadas na educação evidenciou que elas têm levado a diferentes e conjugados formatos de privatização da educação nos países em questão, que vão dos vouchers a charter schools, de contratos de gestão à aquisição de materiais apostilados por sistemas públicos (ADRIÃO; GARCIA, 2014), inclusão da oferta de pacotes educativos, materiais digitais, orientações pedagógicas, hardwares e softwares educativos, procedimentos de avaliação (CAETANO, 2016). Por outro lado, a privatização na educação, como discute Ball (2007), busca incentivar as escolas públicas a agirem e operarem como prestadores privados, a fim de torná- 
las mais competitivas e aumentar os padrões de qualidade, levando à lógica da competência, dos resultados, da premiação, do bônus, do mérito. Tais conceitos não resistem ao simples exame da realidade educacional concreta, como realizado por diversos autores nos referidos países, os quais apontam a real intenção dos reformadores, ou seja, desobrigar o Estado de funções tão caras e complexas como as de educar a população e, ao mesmo tempo, torná-la mais vulnerável e suscetível às incursões do livre mercado e, como último recurso, à privatização.

\section{REFERÊNCIAS}

ADRIÃO, Theresa; GARCIA, Teise. Subsídio Público ao Setor Privado: reflexões sobre a gestão da escola pública no Brasil. Porto Alegre. Revista Políticas Educativas. v.7, p.110-112, 2014.

ADRIÃO, Theresa; PERONI, Vera. A formação das novas gerações como campo para os negócios? In: AGUIAR, Márcia Angela da S.; DOURADO, Luiz Fernandes (Orgs.). A BNCC na contramão do PNE 2014-2024: avaliação e perspectivas. Recife. p.49-54, ANPAE: 2018.

ADRIÃO, Theresa; PERONI, Vera. et. al. Análise das consequências de parcerias firmadas entre municípios brasileiros e o Instituto Ayrton Senna para a oferta educacional. CNPQ, UNESP, 2010 (Relatório de Pesquisa).

AFONSO, Almerindo Janela. Avaliaçao Educacional. Regulaçao e Emancipaçao. $4^{a}$ ed. São Paulo. Cortez Editora: 2009.

AMARAL, Maria Clara Ede. Relações público-privado na educação de Mato Grosso. Tese (Doutorado). Programa de Pós-Graduação em Educação, da Universida-de Estadual de Campinas. Campinas/SP, 2014, 221 p.

BALL, Stephen J. Diretrizes Políticas Globais e Relações Políticas Locais em Educação Currículo sem Fronteiras, v.1, n.2, p.99-116, Jul/Dez 2001.

BALL, Stephen J. Education plc. Understanding private sector participation in public sector education. Routledge, London: 2007.

BALL, Stephen J. Performatividade, Privatização e Pós-Estado do Bem-Estar. Educ. Soc., Campinas, v. 25, n. 89, p. 1105-1126, Set./Dez. 2004. 
BALL, Stephen J. Culture, Cost and Control: Self-Management and Entrepreneurial Schooling in England and Wales. In: SMYTH, John. A Socially Critical View of the Self-Managing School. Routledge Falmer, London: 2004.

BALL, Stephen J.; YOUDELL, Deborah. Hidden Privatisation in Public Education. Preliminary Report, Education International. 5th World Congress Institute of Education, University of London. July 2007.

BALL, Stepehn J.; OLMEDO, Antonio. A 'nova'filantropia, o capitalismo social e as redes de políticas globais em educação. In.: PERONI, Vera Maria V. (Org.). Redefinições das fronteiras entre o público e o privado: implicações para a democratização da educação.Brasília: Liber Livro, p. 33-47, 2013.

BORON, Atílio. Después del saqueo: el Capitalismo Latinoamericano a Comienzos del Nuevo Siglo. In: BORON, Atílio. Estado, Capitalismo y Democracia en América Latina. Buenos Aires: Clacso, p. 15-38, 2003.

BRASIL. Constituição da República Federativa do Brasil de 1988. Brasília, DF, 1988.

. Plano Diretor da Reforma do Aparelho do Estado. Ministério da Administração Federal e Reforma do Estado. 1995.

. Lei $n^{\circ}$ 9.394, de 20 de dezembro de 1996. Estabelece as Diretrizes e Bases da Educação Nacional. Brasília, DF, 1996.

. Lei no 9.637, de 15 de maio de 1998. Dispõe sobre a qualificação de entidades como organizações sociais, a criação do Programa Nacional de Publicização, a extinção dos órgãos e entidades que menciona e a absorção de suas atividades por organizações sociais. Brasilia, DF, 1998.

. Lei no 9.790, de 23 de março de 1999. Dispõe sobre a qualificação de pessoas jurídicas de direito privado, sem fins lucrativos, como Organizações da Sociedade Civil de Interesse Público, institui e disciplina o Termo de Parceria. Brasília, DF, 1999.

BRESSER PEREIRA, Luiz Carlos. A reforma do Estado dos anos 90: lógica e mecanismos de controle. São Paulo, Lua Nova, 1998. no 45, p.49-95. 
CAETANO, Maria Raquel. Redes globais e educação: a rede Latino Americana da sociedade civil para a educação-REDUCA. ANPAE / Série Cadernos ANPAE, v. 41, 2016.

CHUBB, John E.; MOE, Terry M. Politics Markets \& America's Schools. Washington, D.C: The Brookings Institution, 1990.

COSTA, Marilda de Oliveira; AMARAL, Maria Clara E. de. O governo da educação pública de Mato Grosso sob a égide do gerencialismo - o caso do siga. Revista Faed, UNEMAT, v. 24. 2015. Disponível em: < http://www.revistafaed. unemat.br>. Acesso em 28 de novembro de 2016.

COSTA, Marilda. Nova Gestão Pública e redefinição de fronteiras públicoprivadas na educação brasileira. $1^{\circ}$ ed. Curitiba: Appris, 2019.

COURT, Marian; O'NEILL, John. Tomorrow's Schools'in New Zealand: from social democracy to market managerialism. Journal of Educational Administration and History. Vol. 43, No. 2, May 2011, 119-140.

CREDO. Center for Research on Education Outcomes Stanford University. Urban Charter School Study Report on 41 Regions. Stanford, CA, 2015. $<$ http://urbancharters.stanford.edu/download $>$ urban charter school stady report on 41 region pdf. Acesso em 27 de agosto de 2016.

DALE, Roger. Globalização e Educação: demonstrando a existência de uma "Cultura Educacional Mundial Comum" ou localizando uma "Agenda Globalmente Estruturada para a Educação"? Educação e Sociedade, v. 25, n. 87, p.423-460, maio/ago. 2004.

DOURADO Luiz Fernandes; PARO, Vitor Henrique (Orgs.). Políticas Públicas \& Educação Básica. 1. ed. São Paulo: Xamã, 2001.

FLYNN, Norman. Public Sector Management. 2 ed. London: Harvester WheatSheaf, 1993.

HOOD, Christopher. A Public Management for all Seasons? Public Administration, v. 69, p.3-19, Spring 1991. 
LIMA, Licínio C. Apresentação dossiê - Privatização da educação no contexto da(s) "Terceira(s) Via(s)": uma caracterização em análise. Currículo Sem Fronteira. Currículo sem Fronteiras, v. 13, n. 2, p. 177-181, maio/ago. 2013.

LIMA, Licínio C. Diretor(a) de escola pública: unipessoalidade e concentração do poder no quadro de uma relação subordinada. In: Peroni, Vera Maria V. (Org.). Redefinições das fronteiras entre o público e o privado: implicações para a democratização da educação. Brasília: Liber Livro, p. 58-81, 2013.

LIMA, Licínio C. Elementos de hiperburocratização da administração educacional. In: LUCENA, Carlos; SILVA JUNIOR, João dos R.; (Orgs.). Trabalho e educação no século XXI: experiências internacionais. Xamã, São Paulo: p. 129158, 2012.

LIMA, Licínio C. A Escola como Organização Educativa: uma abordagem sociológica. 4. ed. São Paulo: Cortez, 2011.

LIMA, Licínio C. Cidadania e Educação: Adaptação ao mercado competitivo ou participação na democratização da democracia? Educação, Sociedade \& Culturas, n. 23, p.71-90, 2005.

LIMA, Licínio C. O paradigma da educação contábil políticas educativas e perspectivas gerencialistas no ensino superior em Portugal. Revista Brasileira de Educação. n.4, p. 43-59, Jan/Fev/Mar/Abr, 1997.

LIMA, Licínio C; Afonso, Almerindo J. Reformas da Educação Pública. Democratização, Modernização, Neoliberalismo. ed. 1, Porto: Afrontamento, 2002.

LIMA, Licínio C.; AFONSO, Almerindo J. The Promised Land: school autonomy, evaluation and curriculum decision making in Portugal. Educational Review, v. 47, n. 2, 1995.

LIMA, Licínio C.; AFONSO, Almerindo J. A emergência de políticas de racionalização, de avaliação e de controle da qualidade na reforma educativa em Portugal. Educação \& Sociedade. Ano XIV. n. 44, p. 33-49, Abril. 1993. 
LIMA, Licínio C.; GUIMARÃES, Paula. European Strategies in Lifelong Learning - A Critical Introduction Barbara Budrich Publishers, Leverkusen Opladen, Germany, 2011.

NEVES, Lucia Maria Wanderley (Org.). A Nova Pedagogia da Hegemonia Estratégias do capital para educar o consenso. São Paulo: Xamã, 2005.

NEWMAN, Janet; CLARKE, John - Gerencialismo. Educ. Real., Porto Alegre, v. 37, n. 2, p. 353-381, maio/ago. 2012.

O'FLYNN, Janine. From New Public Management to Public Value: Paradigmatic Change and Managerial Implications. The Australian Journal of Public Administration, v. 66, n. 3, p. 353-366, 2007.

O'NEILL, John. The privatisation of public schooling in New Zealand. Journal of Education Policy. v. 26, n. 1, p. 17-31, January, 2011.

OLIVEIRA, Dalila Andrade. (Org.). Gestão democrática da educação; desafios contemporâneos. Petrópolis: Vozes, 1997. Xamã. São Paulo: 2001.

PARO, Vitor Henrique. Gestão democrática da pública escola. 3 ed. Ática, São Paulo: 2000.

PERONI, Vera M. Vidal. Redefinições no papel do Estado e política educacional nos anos1990 no Brasil. Xamã. São Paulo: 2003.

ROBERTSON, Susan; VERGER, Antoni. A origem das parcerias públicoprivada na governança global da educação. Campinas. Educação e Sociedade, v.33, n. 121, p. 1133-1156, out. dez. 2012.

ShIROMA, Eneida O; MORAES, M. C. M. de; EVANGELISTA, O. Política Educacional. DP\&A Editora, Rio de Janeiro: 2004.

SILVA, Maria Vieira. SOUZA, Silvana Aparecida de. Educação e responsabilidade empresarial: "novas" modalidades de atuação da esfera privada na oferta educacional. Educ. Soc., Campinas, vol. 30, n. 108, p. 779-798, out. 2009 
SMYTH, John. The disaster of the "self-managing school" - Genesis, trajectory, undisclosed agenda, and effects. Journal of Education Administration and History, v. 43, n.2, p.95-117, 2011.

TEODORO, Antonio; TORRES, Carlos Alberto. Educação Crítica e Utopia.

Perspectivas para o Século XXI. Porto-Portugal, Afrontamento: 2005.

Sites

http://portal.inep.gov.br

http://urbancharters.stanford.edu

MARILDA DE OLIVEIRA COSTA possui doutorado em educação e pós doutoramento em Ciências da Educação, na Especialidade Administração e Organização Escolar. É professora titular da Faculdade de Educação e Linguagem e do Programa de Pós-Graduação em Educação da Universidade do Estado de Mato Grosso (UNEMAT).E-mail: marildacosta532@gmail.com

Recebido em janeiro de 2019

Aprovado em maio de 2019 